Illinois State University

ISU ReD: Research and eData

Theses and Dissertations

10-16-2017

\title{
The Physical And Psychological Effects Of Standing Desks In Office Workers
}

Hannah Dohm

Illinois State University, hedohm@ilstu.edu

Follow this and additional works at: https://ir.library.illinoisstate.edu/etd

Part of the Kinesiology Commons

\section{Recommended Citation}

Dohm, Hannah, "The Physical And Psychological Effects Of Standing Desks In Office Workers" (2017). Theses and Dissertations. 803.

https://ir.library.illinoisstate.edu/etd/803

This Thesis is brought to you for free and open access by ISU ReD: Research and eData. It has been accepted for inclusion in Theses and Dissertations by an authorized administrator of ISU ReD: Research and eData. For more information, please contact ISUReD@ilstu.edu. 


\title{
THE PHYSICAL AND PSYCHOLOGICAL EFFECTS OF STANDING DESKS IN OFFICE WORKERS
}

\author{
Hannah E. Dohm
}

\section{Pages}

PURPOSE: The purpose of the study was to determine differences in energy expenditure between sitting and standing conditions in typically sedentary office workers. A secondary purpose of this study was to determine if there are mindset differences with regards to job boredom, job stress, and job satisfaction between conditions. METHODS: Participants ( $\mathrm{N}=26$, 4 males and 22 females) were from two moderately sized communities in the Midwest that had standing desk options available to them. Data was collected using BodyMedia SenseWear armbands for energy expenditure and self-reported Likert-scale surveys for psychological data. Intake data included sex, age, height, weight, smoking habits, and dominant hand. Data was collected during four sessions; two sitting sessions where participants were asked to not use their standing desk option, and two standing sessions where participants were allowed to stand as they desired. Data was analyzed using paired-samples t-tests to determine mean differences between energy expenditure and survey data. RESULTS: Results of the $t$-test for energy expenditure indicated the standing condition expended an average of $7.25 \mathrm{kcal}$ more per hour than the sitting condition $(t(24)-3.352, \mathrm{p}=0.003)$. No differences were found between average total survey data or specific question survey results (all $p>0.05$ ). CONCLUSIONS: The results of this study suggest there is a statistically significant increase in energy expenditure when utilizing a standing desk option at the typical office workstation. Participants expressed improvements in mindset, but this difference was not statistically significant. Overall, individuals that participate in 
standing throughout the day rather than strictly sitting can increase energy expenditure while at their normal workstation, potentially resulting in increased weight loss and decreased negative health risk factors for typically sedentary office workers.

KEYWORDS: Standing desks, Office workers, Energy expenditure, Sedentary, Job satisfaction, Job stress, Job boredom 


\section{THE PHYSICAL AND PSYCHOLOGICAL EFFECTS OF STANDING DESKS IN OFFICE WORKERS}

HANNAH E. DOHM

A Thesis Submitted in Partial Fulfillment of the Requirements for the Degree of

MASTER OF SCIENCE

School of Kinesiology and Recreation

ILLINOIS STATE UNIVERSITY 
Copyright 2017 Hannah E. Dohm 


\section{THE PHYSICAL AND PSYCHOLOGICAL EFFECTS OF STANDING DESKS IN OFFICE WORKERS}

HANNAH E. DOHM

COMMITTEE MEMBERS:

Kelly R. Laurson, Chair

Kristen M. Lagally

Dale D. Brown 


\section{ACKNOWLEDGMENTS}

I would like to thank the members of my thesis committee, Dr. Kelly Laurson, Dr.

Kristen Lagally, and Dr. Dale Brown for their support of my project. Also, thank you to Jackie

Sherman for her assistance on distributing and collecting armbands among participants.

H.E.D. 


\section{CONTENTS}

Page

ACKNOWLEDGMENTS

CONTENTS

$\begin{array}{ll}\text { TABLES } & \text { iii }\end{array}$

CHAPTER I: THE PHYSICAL AND PSYCHOLOGICAL EFFECTS OF STANDING

DESKS IN OFFICE WORKERS 1

Introduction $\quad 1$

$\begin{array}{ll}\text { Methods } & 3\end{array}$

Subjects and Procedures $\quad 3$

$\begin{array}{ll}\text { Equipment and Measures } & 4\end{array}$

Data/Statistical Analysis $\quad 5$

$\begin{array}{ll}\text { Results } & 5\end{array}$

$\begin{array}{ll}\text { Discussion } & 10\end{array}$

$\begin{array}{ll}\text { Conclusion } & 13\end{array}$

$\begin{array}{ll}\text { References } & 14\end{array}$

CHAPTER II: EXTENDED LITERATURE REVIEW 17

$\begin{array}{lc}\text { REFERENCES } & 28\end{array}$

APPENDIX: PARTICIPANT JOB SURVEY 33 


\section{TABLES}

Table

Page

$\begin{array}{ll}\text { 1. Subject Characteristics } & 7\end{array}$

2. Energy Expenditure Paired Samples t-test Results 7

3. Paired Samples t-test Results for Average Total Survey Data 8

4. Paired Samples t-test Results for Specific Survey Question Data 9 


\section{CHAPTER I: THE PHYSICAL AND PSYCHOLOGICAL EFFECTS OF STANDING DESKS}

\section{IN OFFICE WORKERS}

\section{Introduction}

Nearly $70 \%$ of adults in the United States are considered to be overweight, with about 38\% being obese ("Obesity and Overweight," n.d.). Obesity can be detrimental to a workplace environment, even increasing rates of workplace injury (Pollack et al., 2007). It was estimated in 2011 that daily workplace-related energy expenditure has decreased significantly over the last couple decades, which may account for the increase in overweight (Church et al., 2011). In general, the greater the level of physical activity a person does, whether leisure or workplace activity, the greater the reduction of risks such as obesity, diseases, and mortality (Probert, Tremblay, \& Connor Gorber, 2008).

Negative health impacts of sedentary behaviors can be concerning to individuals that continue to increase sedentary activities throughout the day. Sedentary behavior has been found to be associated with mortality risks, whether it be all-cause, CVD-related, or other cause, independent of any other factors (Katzmarzyk, Church, Craig, \& Bouchard, 2009). Additional diseases and risk factors can be associated with sedentary behaviors as well. Site-specific cancers, including colon, ovarian, and endometrial, have been related to increased levels of sedentary activity (Thorp, Owen, Neuhaus, \& Dunstan, 2011). Other studies have reported increased risk for diabetes due to high levels of sedentary behavior (Ford et al., 2010). Other conditions including cardiovascular disease, mental disorders, hypertension, and more have been found to increase due to sedentary behavior, independent of physical activity (Thorp, Owen, Neuhaus, \& Dunstan, 2011). If sedentary behaviors are reduced, this may have a positive impact not only on overweight and obesity prevalence, but also decreasing negative health risks as 
previously mentioned including risk of mortality, mental health concerns, cardiovascular disease, diabetes, various types of cancer, and more.

Despite the implementation of corporate wellness programs designed to address some of the previously mentioned health issues, it appears that employees continue to be sedentary during the vast majority of their workday, especially office workers. This immobility throughout the day results in decreased calories burned (Thompson, Foster, Eide, \& Levine, 2008). In order to decrease sedentary behavior and increase physical activity at work, while not sacrificing work efficiency, alternative work methods have been developed. These methods include devices to increase physical activity or change postural position at the typical workstation. Previous research has determined benefits of both types of changes in the workplace; examples include using a walking/stepping workstation or a simple change in sitting device, i.e. chair versus stability ball. The current focus is to decrease time spent strictly sitting throughout the day. Sitstand desks are a new option that provides the individual the option to sit or stand while remaining able to work at their normal workstation.

Working using a sit-stand desk was found to significantly decrease sitting time in call center workers (Straker, Abbott, Heiden, Mathiassen, \& Toomingas, 2013). Previous research has determined an increase in $\mathrm{VO}_{2}$ in students between sitting and standing (Reiff, Marlatt, \& Dengel, 2012). Increases in $\mathrm{VO}_{2}$ could equate to additional weight loss while standing rather than sitting. In a study by Pronk et. al (2012), participants also reported feeling more comfortable, energized, healthier, more focused, more productive, happier, and less stressed as a result of having the sit-stand device installed at their workstation. The combination of physical and mental health benefits potentially created by decreasing sedentary time is of importance. 
Research is needed to determine energy expenditure differences and psychological differences between sitting and standing at work. Few studies exist that have looked at both differences in typically sedentary office workers. Therefore, the purpose of this study was to determine if standing at a workstation increases energy expenditure and improves self-reported levels of job stress, job satisfaction, and job boredom.

\section{Methods}

\section{Subjects and Procedures}

Participants for this study were current office workers in a variety of career settings that possessed a standing desk option at their workstation prior to enrolling in the study. Multiple versions of standing desks were utilized in the study, but the importance of this study was to determine standing versus sitting outcomes, no changes were made to the equipment available to the individuals. The individuals were required to be able to physically stand during their work in order to participate. The subjects in this study included 26 office workers from various areas of work in two Midwest communities. There were 4 male and 22 female participants, ages ranged from 23 to 62 years old. Data collection took place at the workstation during normal working conditions, during typical working hours. The Institutional Review Board (IRB) at Illinois State University approved the protocol and written informed consent was obtained from each participant before the study.

Subjects participated in two conditions. First, data was collected while sitting at work (without using their standing desk) for 2 days. Following, subjects were allowed to use their standing desk for 2 more days, totaling 4 experimental sessions per participant. Armband usage was restricted to working hours while at workstation, starting with the beginning of the workday and ending at the completion of the work day. Time spent standing was not directed; participants 
were able to stand as they chose during the standing sessions. Upon completion of each workday, participants completed a survey of measures of job satisfaction, stress, and boredom. Average measurements of the 2 sitting days and 2 standing days were reported.

\section{Equipment and Measures}

Energy expenditure was measured utilizing a BodyMedia SenseWear (BodyMedia Inc., Pittsburgh, PA, USA) armband (Andre et al., 2006). This armband is worn on the back of the upper left arm. The information collected in an intake data survey (including self-reported measures of height, weight, dominant hand, smoking habits, and date of birth) was utilized to calibrate the armband to the specific participant. The armband sensors include heat-flux, galvanic skin response, and two-way accelerometer. Utilizing the various sensors, the armband provides measures of energy expenditure in the participants. Each participant was provided an armband at the beginning of his or her first testing session; armbands were then collected on the final day of participation. Participants were required to wear the armband during all 4 experimental sessions to compare sitting versus standing energy expenditure.

Data collected from the armbands included various measures on a minute-by-minute basis. The SenseWear software program provided specific measures of total time spent wearing the armband and energy expenditure while wearing the armband. Calculations were performed to determine an average of measured energy expenditure per hour of armband usage. After an average of energy expenditure per hour was determined, an average was calculated for the day. An average was then calculated per condition. All energy expenditure values reported were in kilocalories per hour from the calculations.

At the end of each session, a survey was provided to gather qualitative data regarding the psychological disposition of sitting versus standing. The survey consisted of three areas of 
concern: job boredom, job satisfaction, and job stress. The survey provided to the participants is located in Appendix, for reference. Questions included items referencing, for example, level of tiredness, ability to complete work throughout the day, and amount of stress felt at work.

\section{Data/Statistical Analysis}

All statistical analyses were completed using IBM SPSS Statistics Software version 25 (IBM Corp., Armonk, NY, USA). Descriptive statistics and frequencies were calculated.

To determine differences in mean values between conditions (sitting and standing), a paired-samples t-test was used. One subject did not have armband data collected, as there was a malfunction of the armband; therefore only 25 subjects were included in the data analysis of energy expenditure. The paired-samples t-test was executed to determine mean differences in energy expenditure between sitting and standing.

For the questionnaire data, a sum of responses per day per participant was prepared for each section of the survey; an average was calculated per condition. These averages were then analyzed using paired-samples t-tests to determine differences in standing versus sitting. To determine more specific question results, additional paired-samples t-tests were performed for four specific questions from the survey data. Questions included how often participants got bored throughout the day, how slowly time passed, level of stress during the day, and level of job satisfaction. Not all participants answered all questions or sections of the survey; data analysis was restricted to those with completed responses.

\section{Results}

This study consisted of 26 participants ( 4 male, 22 female) from a variety of backgrounds. The subjects had a mean age of $44.2 \pm 12.3$ years, weight of $78.8 \pm 22.5$ kilograms, 
and height of $169.0 \pm 8.7$ centimeters. Descriptive statistics for all subjects are reported in Table 1.

When comparing mean differences between standing energy expenditure and sitting energy expenditure, there were significant differences in energy expenditure per hour. Sitting averaged $96.2 \mathrm{kcal}$ per hour and standing averaged $103.5 \mathrm{kcal}$ per hour. A paired samples t-test revealed that the standing condition expended an average of $7.25 \mathrm{kcal}$ more per hour than the sitting condition $\mathrm{t}(24),-3.352, \mathrm{p}=0.003$. $\mathrm{T}$-test results for mean differences in energy expenditure can be found in Table 2 .

When comparing mean differences between condition averages for survey data, no statistical differences were found. Job boredom mean sums had no significance $t(25), 1.531, p=$ 0.138. Job stress mean sums were not significant $t(25),-1.180, p=0.249$. Job satisfaction mean sums also had no significance $t(24),-0.247, p=0.807$. Mean differences for average survey data by condition can be found in Table 3 .

Specific question survey data also found no mean statistical differences. All significance levels were greater than the alpha of 0.05 . The question regarding boredom during the day was not significant $\mathrm{t}(25), 1.070, \mathrm{p}=0.295$. When asked how slowly the day went by, participants were found to have no significant difference $t(25), 0.772, p=0.448$. Participants' stress levels were not reported to have significant change $t(25), 0.370, p=0.477$. Finally, when asked how satisfied they were with their job, there was no significant difference between condition $t(24)$, $0.866, p=0.395$. Mean differences for the specific survey responses can be found in Table 4 . 
Table 1

Subject Characteristics

\begin{tabular}{cc}
\hline & Mean \pm Standard Deviation \\
\hline Height $(\mathrm{cm})$ & $169.0 \pm 12.3$ \\
Weight $(\mathrm{kg})$ & $78.8 \pm 22.5$ \\
Age (years) & $44.2 \pm 12.3$ \\
\hline
\end{tabular}

Note: sample size $=26$; male $=4$, female $=22$

Table 2

Comparison of energy expenditure between sitting and standing conditions

\begin{tabular}{llllllll}
\hline & $\begin{array}{l}\text { Mean } \\
(\text { kcal/hour })\end{array}$ & SD & T & p-value & $\begin{array}{l}\text { Mean } \\
\text { Difference }\end{array}$ & $\begin{array}{l}\text { 95\% CI } \\
\text { LB }\end{array}$ & $\begin{array}{l}\text { 95\% CI } \\
\text { UB }\end{array}$ \\
\hline $\begin{array}{l}\text { Sitting } \\
\text { Condition }\end{array}$ & 96.2 & 16.8 & -3.352 & $0.003^{*}$ & 7.25 & 2.78 & 11.71 \\
$\begin{array}{l}\text { Standing } \\
\text { Condition }\end{array}$ & 103.5 & 20.1 & & & & & \\
\hline
\end{tabular}

Note: Sample size $=25 .{ }^{*}$ Significant at $\mathrm{p}<0.05$. 
Table 3

Paired Samples T-Test Results for Average Total Survey Responses

\begin{tabular}{|c|c|c|c|c|c|c|c|}
\hline & Mean & SD & $\mathrm{T}$ & p-value & $\begin{array}{l}\text { Mean } \\
\text { Difference }\end{array}$ & $\begin{array}{l}95 \% \text { CI } \\
\text { LB }\end{array}$ & $\begin{array}{l}95 \% \\
\text { CI UB } \\
\end{array}$ \\
\hline \multicolumn{8}{|c|}{ Job Boredom } \\
\hline Sitting & 33.23 & 9.27 & 1.531 & 0.138 & 2.077 & -0.72 & 4.87 \\
\hline Standing & 31.25 & 6.84 & & & & & \\
\hline \multicolumn{8}{|l|}{ Job Stress } \\
\hline Sitting & 16.75 & 2.07 & -1.180 & 0.249 & 0.413 & -1.15 & 0.31 \\
\hline Standing & 17.16 & 1.49 & & & & & \\
\hline \multicolumn{8}{|c|}{ Job Satisfaction } \\
\hline Sitting & 36.24 & 2.76 & -0.247 & 0.807 & 0.100 & -0.94 & 0.74 \\
\hline Standing & 36.34 & 2.95 & & & & & \\
\hline
\end{tabular}

Note: Sample size $=26$ for job boredom and job stress. Sample size $=25$ for job satisfaction 
Table 4

Paired Samples T-Test Results for Specific Survey Data

\begin{tabular}{|c|c|c|c|c|c|c|c|}
\hline & Mean & SD & $\mathrm{T}$ & p-value & $\begin{array}{l}\text { Mean } \\
\text { Difference }\end{array}$ & $\begin{array}{l}95 \% \text { CI } \\
\text { LB }\end{array}$ & $\begin{array}{l}95 \% \\
\text { CI } \\
\text { UB }\end{array}$ \\
\hline \multicolumn{8}{|c|}{ Did you often get bored with your work today? } \\
\hline Sitting & 1.71 & 0.65 & 1.070 & 0.295 & 0.135 & -0.12 & 0.39 \\
\hline Standing & 1.58 & 0.56 & & & & & \\
\hline \multicolumn{8}{|c|}{ Did the day seem to go by slowly? } \\
\hline Sitting & 1.94 & 1.00 & 0.772 & 0.448 & 0.135 & -0.22 & 0.49 \\
\hline Standing & 1.80 & 0.74 & & & & & \\
\hline \multicolumn{8}{|c|}{ I often feel stressed throughout the day. } \\
\hline Sitting & 2.29 & 0.77 & 0.723 & 0.477 & 0.096 & -0.18 & 0.37 \\
\hline Standing & 2.19 & 0.94 & & & & & \\
\hline \multicolumn{8}{|c|}{ Overall, I am satisfied with my job. } \\
\hline Sitting & 4.40 & 0.52 & 0.866 & 0.395 & 0.100 & -0.14 & 0.34 \\
\hline Standing & 4.30 & 0.72 & & & & & \\
\hline
\end{tabular}

Note: Sample size $=26$ for job boredom, slowness of day, and job stress. Sample size $=25$ for job satisfaction 


\section{Discussion}

The data collected in this study show the importance of standing desk usage for office workers. The current study has determined there is a significant difference between sitting and standing energy expenditure while working. Results of this study indicate an average increase of 7 kilocalories per hour while using a standing desk option at the typical workstation.

Previous research by Church et. al (2011) found that the increasing number of overweight or obese individuals may be due to the reduced energy expenditure at work. In a study by Probert and colleagues (2008), it was noted that greater health benefits have been found in individuals that expend a higher amount of energy while at work. Thompson, Foster, Eide, \& Levine (2008) determined that lack of movement during the day results in decreased calories burned. Since many individuals possess a workstation that consists of a desk and sedentary chair option, in order to be effective at work, an individual is required to be sedentary, unless provided a standing desk option. In agreement with previous research from Levine \& Miller (2007), sitstand desks can be a method of decreasing the sedentary nature of work we have been seeing. Without sacrificing any work time, standing desk options can replace strict sitting time in typically sedentary office workers.

Other previous research by Levine \& Miller (2007) found that standing desks have been found to significantly increase energy expenditure. Reiff, Marlatt, \& Dangal (2012) found that standing at a desk rather than sitting was found to increase $\mathrm{VO}_{2}$ and therefore energy expenditure by 0.34 kilocalories per minute. This value is somewhat larger than the results of the current study; however the Reiff (2012) study was completed on children. If we have found an alternative that does not impact productivity or efficiency of work tasks, standing desks could benefit many individuals. 
Similar to the previous study by Benden, Blake, Wendel, \& Huber (2011), which determined that individuals using standing desks burned an average of 0.18 kilocalories per minute more than individuals using typical seated desks, standing was found to increase energy expenditure by an average of $7 \mathrm{kcal}$ per hour in the participants measured in this study. This could be a potential increase of approximately $56 \mathrm{kcal}$ per typical 8-hour workday on average. Even minor increases such as those found in this study could be beneficial to overweight and obese individuals that typically sit during work. Any increase in energy expenditure could relate to potential for weight loss given all other factors remain constant.

While psychological survey data from this study did not have significant results, comments from participants were positive. Individuals expressed interest in continuing to use standing desk options as a means of changing of routine sitting throughout the day. The survey data may not have been the best representation of the results as they were self-reported Likertscale type questions in which many individuals differ strictly due to tasks they were performing on a given day or other factors in the workplace environment.

Previous research has shown individuals that use sit-stand desks at work feel more comfortable, full of energy, healthier, more focused and productive at work, less stressed, and overall happier (Pronk et. al, 2012). Other studies on standing desks have determined that participants typically feel more alert, have increased levels of concentration, and reduced amounts of fatigue (Chau et. al, 2014). During the current study, while not having statistically significant results, participants overall expressed an interest in the standing desks because it made them feel better throughout the day. Participants that previously used the standing option regularly were particularly upset on the days standing was limited. 
Several limitations to this study exist. The study was based around participant freedom to choose if/when they were standing on days where standing was allowed. No direction was given to take or not take standing breaks, or on the duration of the standing breaks. While standing times were not reported, participants seemed eager to stand when they were able based on their comments upon completion of the sessions. Another limitation is that individuals do not do the same tasks throughout the day; each participant had a different schedule and work tasks to complete throughout the day. The study was short in duration with only two days of sitting and two days of standing measured. Finally, the study had a small sample size. While it is not anticipated the results would differ with increased participation, future research should be done with greater number of participants and variety of workplace environments to expand the generalizability of the results.

Limitations to the psychological data, i.e. survey data, mainly include the self-reported aspect. Individuals may have a variety of reasons for responding to a survey as they do. On different occasions, each individual may have a different response to the same question for a variety of reasons.

Future research could focus on consistency of standing periods across all participants. For example, instructing participants to stand for 10 minutes of every hour, or different increments by groups. Also, closer monitoring of participation to wear the armband and utilize the standing desk could be beneficial to accuracy of results. Similar work tasks could be completed in a laboratory setting to eliminate any potential error from results since some individuals may have more active work tasks that induce more energy expenditure.

While it was not determined in the current study if duration of standing time impacts, future research should be done to determine if additional standing time affects energy 
expenditure in a positive way or if there is a certain amount of standing time recommended for the most beneficial results in office workers. Otherwise, future research could focus on the optimal duration of standing or number of standing periods throughout the day for the most health benefits.

\section{Conclusion}

The present study demonstrates significant differences between energy expenditure while standing versus sitting in typical office workers. The study provides evidence that sit-stand desk options may be beneficial as a means of increasing total daily energy expenditure and decreasing sedentary time. Since sit-stand desk options are an effective method of decreasing sitting behavior in office workers, it may be beneficial for employers to add this option to the workstations of their employees. While the current study did not find statistically significant differences between self-reported measures of job boredom, job stress, and job satisfaction, previous studies have indicated positive psychological benefits from standing while working. Future research could evaluate other psychological adaptations to working while standing. Other research should be completed to determine the additive effects of additional standing time during work. 


\section{References}

Andre, D., Pelletier, R., Farringdon, J., Safier, S., Talbott, W., Stone, R., ... others. (2006). The development of the SenseWear ${ }^{\circledR}$ armband, a revolutionary energy assessment device to assess physical activity and lifestyle. BodyMedia Inc.

Benden, M. E., Blake, J. J., Wendel, M. L., \& Huber, J. C. (2011). The Impact of Stand-Biased Desks in Classrooms on Calorie Expenditure in Children. American Journal of Public Health, 101(8), 1433-1436. https://doi.org/10.2105/AJPH.2010.300072

Chau, J. Y., Daley, M., Srinivasan, A., Dunn, S., Bauman, A. E., \& van der Ploeg, H. P. (2014). Desk-based workers' perspectives on using sit-stand workstations: a qualitative analysis of the Stand@Work study.BMC Public Health, 14(1),752.

Church, T. S., Thomas, D. M., Tudor-Locke, C., Katzmarzyk, P. T., Earnest, C. P., Rodarte, R. Q., ... Bouchard, C. (2011). Trends over 5 Decades in U.S. Occupation-Related Physical Activity and Their Associations with Obesity. PLoS ONE, 6(5), e19657. https://doi.org/10.1371/journal.pone.0019657

Ford, E. S., Schulze, M. B., KröGer, J., Pischon, T., Bergmann, M. M., \& Boeing, H. (2010). Television watching and incident diabetes: Findings from the European Prospective Investigation into Cancer and Nutrition-Potsdam Study. Journal of Diabetes, 2(1), 23-27. https://doi.org/10.1111/j.1753-0407.2009.00047.x

Katzmarzyk, P. T., Church, T. S., Craig, C. L., \& Bouchard, C. (2009). Sitting Time and Mortality from All Causes, Cardiovascular Disease, and Cancer: Medicine \& Science in Sports \& Exercise, 41(5), 998-1005. https://doi.org/10.1249/MSS.0b013e3181930355 
Levine, J. A., \& Miller, J. M. (2007). The energy expenditure of using a "walk-and-work" desk for office workers with obesity. British Journal of Sports Medicine, 41(9), 558-561. https://doi.org/10.1136/bjsm.2006.032755

Obesity and Overweight. (n.d.). Retrieved December 3, 2016, from http://www.cdc.gov/nchs/fastats/obesity-overweight.htm

Pollack, K. M., Sorock, G. S., Slade, M. D., Cantley, L., Sircar, K., Taiwo, O., \& Cullen, M. R. (2007). Association between Body Mass Index and Acute Traumatic Workplace Injury in Hourly Manufacturing Employees. American Journal of Epidemiology, 166(2), 204-211. https://doi.org/10.1093/aje/kwm058

Probert, A. W., Tremblay, M. S., \& Connor Gorber, S. (2008). Desk potatoes: the importance of occupational physical activity on health. Canadian Journal of Public Health $=$ Revue Canadienne De Sante Publique, 99(4), 311-318.

Pronk, N. P., Katz, A. S., Lowry, M., \& Payfer, J. R. (2012). Reducing occupational sitting time and improving worker health: the take-a-stand project, 2011. Preventing Chronic Disease, 9.

Reiff, C., Marlatt, K., \& Dengel, D. R. (2012). Difference in caloric expenditure in sitting versus standing desks. Journal of Physical Activity and Health, 9(7), 1009-1011.

Straker, L., Abbott, R. A., Heiden, M., Mathiassen, S. E., \& Toomingas, A. (2013). Sit-stand desks in call centres: Associations of use and ergonomics awareness with sedentary behavior. Applied Ergonomics, 44(4), 517-522. https://doi.org/10.1016/j.apergo.2012.11.001 
Thompson, W. G., Foster, R. C., Eide, D. S., \& Levine, J. A. (2008). Feasibility of a walking workstation to increase daily walking. British Journal of Sports Medicine, 42(3), 225228; discussion 228. https://doi.org/10.1136/bjsm.2007.039479

Thorp, A. A., Owen, N., Neuhaus, M., \& Dunstan, D. W. (2011). Sedentary Behaviors and Subsequent Health Outcomes in Adults. American Journal of Preventive Medicine, 41(2), 207-215. https://doi.org/10.1016/j.amepre.2011.05.004 


\section{CHAPTER II: EXTENDED LITERATURE REVIEW}

Current topics in the public health include physical activity, physical inactivity, sedentary behaviors, and obesity. There has been an interest in increasing physical activity in typically sedentary individuals to help combat the issue of obesity. Various aspects of life can be incorporated including leisure and occupational activities. Many individuals spend the majority of their day at work, meaning the largest portion of total energy expenditure comes from occupational activities. If that is when most sedentary behavior takes place, the most logical area to combat obesity could come from activities occurring at work.

This review will encompass: the definition of sedentary behavior, the health impacts of sedentary behavior, energy expenditure during various activities, the prevalence of sedentary behavior, implications of occupational settings on sedentary behavior and if breaks in sedentary activity are helpful. It will also review previous research on workplace interventions for decreasing sedentary behavior and previous qualitative research with regards to sit-stand desks. The review is helpful in evaluating the most effective methods of decreasing sedentary time, specifically during occupational activities involving sedentary behavior.

Sedentary behavior is a common topic in exercise and sport literature. Sedentary behavior can have multiple definitions, including a certain level of energy expenditure or a certain postural position. A definition was developed for journal editors to have consistency; sedentary behavior was defined as any waking behavior characterized by an energy expenditure less than or equal to 1.5 METs while in a sitting or reclining posture; inactive is used to describe those who are performing insufficient amounts of moderate- to vigorous-intensity physical activity (Sedentary Behaviour Research Networ, 2012). Sedentary behaviors can include time spent sitting during transportation/commuting, in the workplace and at home, and during leisure 
activities (Thorp, Owen, Neuhaus, \& Dunstan, 2011). It is also important to note the differing levels of physical activity throughout the day; there is time for both sedentary behavior and moderate-to-vigorous physical activity (Wilmot et al., 2012). The important factor is the ratio in which the activities are completed. There must be a balance of physical activity and sedentary activity. The impact of sedentary behaviors on health outcomes is fairly difficult to measure, longitudinal studies are required to strengthen the evidence as an adult health risk.

The negative health impacts of sedentary behaviors are concerning to a population of individuals that continue to increase sedentary activities. Sedentary behavior has been found to be associated with several causes of mortality. An increased risk for all-cause, CVD-related, and all other causes mortality in both men and women, independent of BMI and physical activity results from sedentary behaviors (Katzmarzyk, Church, Craig, \& Bouchard, 2009). Ultimately, participating in sedentary activity could increase your chances of death by a variety of causes.

Other diseases have also been found to be associated with sedentary behaviors. Site specific-cancers, including ovarian, colon, and endometrial cancers have been consistently related to high levels of sedentary behavior (Thorp, Owen, Neuhaus, \& Dunstan, 2011). Engaging in high levels of sedentary behavior also induces an increased risk for diabetes (Ford et al., 2010). Decreasing sedentary time can positively impact diabetes prevention (Wilmot et al., 2012). Other conditions that have been found to increase risk due to sedentary behavior, independent of physical activity time, include cardiovascular disease, mental disorders, hypertension, and more (Thorp, Owen, Neuhaus, \& Dunstan, 2011). Any of the above mentioned diseases could have a negative impact on physical health as well as mental health, resulting in changing a life entirely. If it becomes an issue throughout the population, it could change our entire society more than it already has. 
Finally, sedentary behaviors in children or adolescence are a predictor of obesity/weight gain in adulthood (Erik Landhuis, Poulton, Welch, \& Hancox, 2008). If we are setting up our younger generation for failure, we should determine ways to improve the issue. Knowing negative impacts should provide reason for experts in the field to determine the cause and put an end to the sedentary behavior epidemic by finding beneficial interventions.

Adults can meet guidelines of physical activity, but if they sit for long periods of time, they are still compromising their metabolic health (Owen, Healy, Matthews, \& Dunstan, 2010). There are no specific guidelines issued with regards to sitting time. Adults tend to self-report majority of their waking hours either sitting or in light intensity activity (Owen, Healy, Matthews, \& Dunstan, 2010). Time spent sitting is occupying time that could be spent in physical activity.

Findings suggest that standing, involving isometric contraction of postural muscles and low levels of energy expenditure, elicit EMG and skeletal muscle changes. However, in the past this type of standing would have been considered sedentary behavior due to lack of movement and energy expenditure (Hamilton, Healy, Dunstan, Zderic, \& Owen, 2008). Thus, standing could be an alternative to sitting in various activities in order to decrease sedentary behaviors.

Various methods of determining sedentary behavior and time spent participating in sedentary activities exist in the literature; from the standard methods of calorimetry or doublylabeled water to consumer-type products such as wrist monitors, etc. In 2000, Levine and partners determined a list of varying energy expenditures during different activities. They measured energy expenditure using an indirect calorimeter in a controlled laboratory setting. The energy expenditure for various activities was reported. Significant differences existed between resting values and sitting while fidgeting, standing motionless, and standing while fidgeting; 
fidgeting activities increased energy expenditure in each subject compared to motionless rates (Levine, Schleusner, \& Jensen, 2000). If energy expenditure differences exist between resting values and the various postural positions, future research may be able to determine methods of implementation to decrease sedentary behaviors and their negative outcomes.

According to the Centers for Disease Control and Prevention, around $70 \%$ of adults in the United States are considered to be overweight, with about $38 \%$ of that being an obese population (“Obesity and Overweight," n.d.). Obesity can impact many aspects of life, physically, mentally, emotionally, etc.. Obesity can be detrimental to a workplace environment, even increasing rates of workplace injury (Pollack et al., 2007). It was estimated in 2011 that daily workplace-related energy expenditure has decreased significantly, which may account for the increase in overweight individuals (Church et al., 2011). The higher the level of physical activity in the workplace, the greater the health benefits (Probert, Tremblay, \& Connor Gorber, 2008).

Trends of energy expenditure in the workplace depend on the type of industry. Overall, from 1960 to 2008, there was a drop in occupation-related daily energy expenditure of 140 calories for men and 124 calories for women (Church et al., 2011). Obese individuals have been noted to spend, on average, over 2 hours longer per day sitting than average individuals (Levine, 2005). Church et al. also determined that sedentary and light activity has increased while moderate physical activity has decreased.

On average, individuals spend $57 \%$ of their waking hours sedentary, $39 \%$ in light intensity activity, and only $4 \%$ in moderate- to vigorous-intensity time (Healy et al., 2008). It has been found that if an individual's usual work habits involve mostly sitting, their leisure time tends to be more sedentary also; while those who are more active at work tend to be more active during leisure time (Probert, Tremblay, \& Connor Gorber, 2008). These increases in sedentary 
behavior could account for the increase in mean body weight over the last few decades. If lifestyle changes can be created in the workplace, they could translate into leisure time as well.

Overall, total daily activity time is around 8 hours per day; occupational time is around 46 hours per day depending on gender; occupational activity was the major determinant of physical activity levels (Csizmadi, Siou, Friedenreich, Owen, \& Robson, 2011). This study also suggested that even increasing levels of light physical activity (between 1.5 and 3 METs) would be helpful in inactive populations. Csizmadi et al. 2011 also determined that even if individuals obtained the recommended levels of physical activity, they still would not have increased their energy expenditure enough to reclassify themselves based on physical activity levels, since they had not decreased their sedentary activities. A balance of increasing physical activity while also decreasing sedentary activity needs to happen.

One study determined that individuals with the highest levels of occupational physical activity and leisure-time physical activity showed a protective association for any chronic disease, the most protective being heart disease (Probert, Tremblay, \& Connor Gorber, 2008). If interventions could be determined to increase both occupational physical activity and leisuretime physical activity levels, perhaps we could improve the obesity problem and decrease sedentary behavior risks.

The previous studies are why intervention studies have begun to determine means of increasing energy expenditure during occupational hours. Many programs have attempted to increase physical activity during work hours. A variety of options exist including sitting on a therapy ball rather than a chair, using a stepping device, walking workstations, standing desks, and many more. Most previous intervention studies have focused specifically on achieving moderate-to-vigorous activity level guidelines, rather than decreasing sedentary time. 
Despite the implementation of the previously mentioned interventions as well as nutrition education, it still appears that employees tend to be sedentary during the vast majority of their workday, especially office workers. Immobility throughout the day results in decreased calories burned (Thompson, Foster, Eide, \& Levine, 2008). In order to decrease sedentary behavior and increase physical activity at work, while not sacrificing work efficiency, alternative work methods have been developed. Cardiometabolic health can also benefit from various workstation options, whether they are standing or stepping stations (Lopez-Jimenez, 2015). Many interventions include interrupting work schedules or occupying breaks to incorporate activity into the day, but if alternatives can be found to promote decreased sedentary time while still able to work as normal, they should be explored.

Since majority of the waking weekday is spent at work, work is the predominant predictor of non-exercise activity. "Walk while you work" desks could change the typical office workstations into activity stations. Walk-and-work desks have been associated with significant increases in energy expenditure above sitting results (Levine \& Miller, 2007). Levine \& Miller (2007) determined that individuals tolerated walking work; since they were able to use their computer as normal while still participating in physical activity, there were no interruptions to their workday. If there is no interruption in normal work tasks, walking workstations could be a decent option for workplaces if the feasibility of installing the desks and the financial ability exists.

Significant associations of BMI and waist circumference benefits have been observed when time is spent stepping rather than standing or sitting (Healy, Winkler, Owen, Anuradha, \& Dunstan, 2015). Standing has also been found to have beneficial associations with lipids and fasting blood glucose levels according to Healy et al. 2015; treadmill desk options may be the 
best approach with regards to adiposity benefits. In all, preliminary evidence shows that standing is beneficial for cardio-metabolic risk factors, especially lipid metabolism. If obese individuals spent the same amount of time, on average, 152 minutes per day, standing as lean individuals, they would spend approximately an additional 350 calories per day (Levine, 2005). If this is the case, standing could be promoted in the workplace setting to decrease risks of sedentary behaviors.

Sitting time has been found to be reduced if individuals are provided an alternative while being able to work at their normal workstation. Pronk et al. (2012) found that upper back and neck pain declined significantly when standing desks were available, they also found that significant improvements existed for fatigue, vigor, tension, confusion, depression, and total mood change while standing options were available to the participants. The same study determined that if the standing option was removed, the results returned to baseline values. In the Pronk study, participants reported feeling more comfortable, energized, healthier, more focused, more productive, happier, and less stressed as a result of having the sit-stand device installed at their workstation (Pronk, Katz, Lowry, \& Payfer, 2012).

Students have also been found to benefit from standing. Significant increases in $\mathrm{VO}_{2}$ were seen in students from sitting to standing in all subjects, therefore determining increases in caloric expenditure from sitting to standing (Reiff, Marlatt, \& Dengel, 2012). Using the results of the Reiff study, additional caloric expenditure could equate to additional weight loss of around 6 pounds per year, simply by standing at a desk rather than sitting. Another study from Benden et al. (2011) found that standing at school also improved behavior, attention/focus, and classroom performance in students. If we could begin implementing standing desk options in the classroom, 
it could carry into an individual's future career habits as well if they get used to standing while working at school at a younger age.

Attempts at reducing sedentary time come from a variety of areas. Results of one study determined that people who do not exercise regularly are willing and able to increase movement activities at work if regularly prompted to do so, based on self-reporting (Cooley \& Pedersen, 2013). This means if all workplaces that put a prompt system in place to remind individuals to take a break from sitting, the impact of postural changes could be stronger. Evans et al. (2012) determined that with prompts, there was no difference on total time spent sitting, but the number of and time spent sitting for prolonged durations was reduced due to prompting and education. Such reminders could prompt individuals to take a break from sitting occasionally. These reminders could help reduce long duration uninterrupted sitting periods.

Studies suggest that simple breaks in sedentary time have been found beneficial to decreasing risks. Ideas include simply transitioning from sitting to standing position, or from standing still to beginning to walk (Owen, Healy, Matthews, \& Dunstan, 2010). Independent of total sedentary time, moderate-to-vigorous intensity time, and mean intensity of the breaks, more interruptions in sedentary time were associated with beneficial results in metabolic variables (Healy et al., 2008). The variables tested by Healy included adiposity measures, triglycerides, and 2-h plasma glucose levels. The findings suggest that not only is the amount of sedentary time important, also how it is accumulated and the duration of uninterrupted sitting periods. Nonsitting alternatives in various environments could be beneficial to the human population such as at the workplace, entertainment venues, in public settings, and more.

It has been recommended to limit sitting time to a maximum of 2 hours per day, and to stand up and move after 30 minutes of strictly sitting (Owen et al., 2011). Other 
recommendations exist that state no more than 2 hours during a typical workday should be spent sitting (Chau et al., 2010). Therefore, workplace alternatives that offer the ability to change postural positions should be researched. If standing improves sedentary risks, and recommendations include moving after certain amounts of time in strict sitting, workplaces should incorporate the ability to change postural position while still being able to work. Sit-stand desk options are an alternative to offer such changes. Working using a sit-stand desk was found to significantly decrease sitting time in call center workers (Straker, Abbott, Heiden, Mathiassen, \& Toomingas, 2013).

Several studies have looked at the use of standing desks in different settings to determine if they are beneficial in regards to health benefits. One study determined that individuals using standing desks burned an average of 0.18 kilocalories per minute more than individuals using typical seated desks (Benden, Blake, Wendel, \& Huber, 2011). Since standing desks have been found to expend more energy and calories, they may be beneficial to decreasing sitting time and improving sedentary health risks.

Sit-stand workstations have been created to allow individuals to sit and stand as they please while working. They consist of height adjustable worktables and chairs, the work surface and sitting position can be elevated to a standing position (Ebara et al., 2008). These sit-stand desks come in a variety of versions, including mechanical or electronic height control, only keyboard surface height adjustment, and more.

Employers specifically target the methods to reduce sitting time while not interrupting work time (Chau et al., 2014). The goal is to be able to complete normal work tasks in the normal work location and with normal productivity rates. Cost effectiveness has also been a concern, not all workplaces may be able to install the best option, but if any standing option is 
beneficial in any mechanism it could be more feasible. The study by Chau determined that participants found had increased productivity due to increased alertness, concentration, and reduced fatigue, particularly during the latter part of the day.

Performance could also be negatively impacted depending on how the individual reacts to a change in postural position while at their normal workstation. Research to determine error estimates or decreased work efficiency is important when changing the work environment. Ebara et al. (2008) determined there was higher work performance while using a sit-stand desk compared to other conditions; in previous research long durations of sitting has been found to negatively impact work performance.

Psychological aspects of work are also impacted by workstation and sedentary behaviors. Other benefits of changing posture while working with an alternative to the typical sitting desk include higher job satisfaction and arousal, as well as less job stress and boredom (Sliter \& Yuan, 2015). Motivation to participate in using sit-stand desks comes from a variety of factors. Participants reported they were interested in decreasing musculoskeletal discomfort, decreasing fatigue, attempting to improve mood, increasing productivity, and more by using the sit-stand desk (Grunseit, Chau, van der Ploeg, \& Bauman, 2013). If we are able to improve all aspects of an individual's life by simply giving them autonomy to control their postural position while at their regular workstation, it could prove to be more beneficial than changing one minor aspect in the workplace.

There have also been studies previously to determine if too much standing is harmful in the workplace. Halim et al. (2012) examined the relationship between certain occupations that typically stand and the muscle behaviors during standing. They found that fatigue occurs in the lower extremities and lower postural muscles most frequently due to performing work in the 
standing position throughout the day. The study also determined that posture of the workers significantly deviated from neutral throughout the day. It was reported that standing with intermittent sitting is the best solution to minimize discomfort during working tasks (Halim, Omar, Saman, \& Othman, 2012). Sitting is a less strenuous activity because it requires fewer muscles to stabilize the body. The opposite could be held true when comparing sitting work during majority of the day, using more muscles is beneficial. Sitting in long periods of time is also not good for health. It is important to find a balance between sitting and standing activities, especially for workers.

While it may be an early period of research for interventions to decrease sedentary behavior, this is an important area of study. Sedentary behaviors have been found to have detrimental outcomes if not balanced by proper postural changes, breaks in sitting time, or increasing energy expenditure. The previous research has determined many benefits of decreasing sedentary behavior. Since most of a typical individual's waking time is spent at work, it is important to develop options to modify the amount of sedentary time while at work. Many of the current options involve time spent away from the desk, rather than intervening while at an individual's normal workstation.

Research should continue to discover the benefits of the variety of methods of changing postural patterns while at work. Some options include increasing physical activity while others are strictly postural change options. The sit-stand desk option seems to allow autonomy for the individual to change postural position as they desire, and to remain at their normal workstation. Current focus is to determine the impact of standing during normal work conditions on energy expenditure and psychological benefits. 


\section{REFERENCES}

Andre, D., Pelletier, R., Farringdon, J., Safier, S., Talbott, W., Stone, R., ... others. (2006). The development of the SenseWear ${ }^{\circledR}$ armband, a revolutionary energy assessment device to assess physical activity and lifestyle. BodyMedia Inc.

Benden, M. E., Blake, J. J., Wendel, M. L., \& Huber, J. C. (2011). The Impact of Stand-Biased Desks in Classrooms on Calorie Expenditure in Children. American Journal of Public Health, 101(8), 1433-1436. https://doi.org/10.2105/AJPH.2010.300072

Chau, J. Y., Daley, M., Srinivasan, A., Dunn, S., Bauman, A. E., \& van der Ploeg, H. P. (2014). Desk-based workers' perspectives on using sit-stand workstations: a qualitative analysis of the Stand@Work study.BMC Public Health, 14(1), 752.

Chau, J. Y., der Ploeg, H. P. van, van Uffelen, J. G. Z., Wong, J., Riphagen, I., Healy, G. N., ... Brown, W. J. (2010). Are workplace interventions to reduce sitting effective? A systematic review. Preventive Medicine, 51(5), 352-356. https://doi.org/10.1016/j.ypmed.2010.08.012

Church, T. S., Thomas, D. M., Tudor-Locke, C., Katzmarzyk, P. T., Earnest, C. P., Rodarte, R. Q., ... Bouchard, C. (2011). Trends over 5 Decades in U.S. Occupation-Related Physical Activity and Their Associations with Obesity. PLoS ONE, 6(5), e19657. https://doi.org/10.1371/journal.pone.0019657

Cooley, D., \& Pedersen, S. (2013). A Pilot Study of Increasing Nonpurposeful Movement Breaks at Work as a Means of Reducing Prolonged Sitting. Journal of Environmental and Public Health, 2013, 1-8. https://doi.org/10.1155/2013/128376 
Csizmadi, I., Siou, G. L., Friedenreich, C. M., Owen, N., \& Robson, P. J. (2011). Hours spent and energy expended in physical activity domains: results from the Tomorrow Project cohort in Alberta, Canada. International Journal of Behavioral Nutrition and Physical Activity, 8(1), 110.

Ebara, T., Kubo, T., Inoue, T., Murasaki, G.-I., Takeyama, H., Sato, T., ... others. (2008). Effects of adjustable sit-stand VDT workstations on workers' musculoskeletal discomfort, alertness and performance. Industrial Health, 46(5), 497-505.

Erik Landhuis, C., Poulton, R., Welch, D., \& Hancox, R. J. (2008). Programming Obesity and Poor Fitness: The Long-term Impact of Childhood Television. Obesity, 16(6), 14571459. https://doi.org/10.1038/oby.2008.205

Evans, R. E., Fawole, H. O., Sheriff, S. A., Dall, P. M., Grant, P. M., \& Ryan, C. G. (2012). Point-of-Choice Prompts to Reduce Sitting Time at Work. American Journal of Preventive Medicine, 43(3), 293-297. https://doi.org/10.1016/j.amepre.2012.05.010

Ford, E. S., Schulze, M. B., KröGer, J., Pischon, T., Bergmann, M. M., \& Boeing, H. (2010). Television watching and incident diabetes: Findings from the European Prospective Investigation into Cancer and Nutrition-Potsdam Study. Journal of Diabetes, 2(1), 23-27. https://doi.org/10.1111/j.1753-0407.2009.00047.x

Grunseit, A. C., Chau, J. Y.-Y., van der Ploeg, H. P., \& Bauman, A. (2013). “Thinking on your feet": A qualitative evaluation of sit-stand desks in an Australian workplace. BMC Public Health, 13(1), 365 .

Halim, I., Omar, A. R., Saman, A. M., \& Othman, I. (2012). Assessment of Muscle Fatigue Associated with Prolonged Standing in the Workplace. Safety and Health at Work, 3(1), 31-42. https://doi.org/10.5491/SHAW.2012.3.1.31 
Hamilton, M. T., Healy, G. N., Dunstan, D. W., Zderic, T. W., \& Owen, N. (2008). Too little exercise and too much sitting: Inactivity physiology and the need for new recommendations on sedentary behavior. Current Cardiovascular Risk Reports, 2(4), 292-298. https://doi.org/10.1007/s12170-008-0054-8

Healy, G. N., Dunstan, D. W., Salmon, J., Cerin, E., Shaw, J. E., Zimmet, P. Z., \& Owen, N. (2008). Breaks in Sedentary Time: Beneficial associations with metabolic risk. Diabetes Care, 31(4), 661-666. https://doi.org/10.2337/dc07-2046

Healy, G. N., Winkler, E. A. H., Owen, N., Anuradha, S., \& Dunstan, D. W. (2015). Replacing sitting time with standing or stepping: associations with cardio-metabolic risk biomarkers. European Heart Journal, 36(39), 2643-2649. https://doi.org/10.1093/eurheartj/ehv308

Katzmarzyk, P. T., Church, T. S., Craig, C. L., \& Bouchard, C. (2009). Sitting Time and Mortality from All Causes, Cardiovascular Disease, and Cancer: Medicine \& Science in Sports \& Exercise, 41(5), 998-1005. https://doi.org/10.1249/MSS.0b013e3181930355

Levine, J. A. (2005). Interindividual Variation in Posture Allocation: Possible Role in Human Obesity. Science, 307(5709), 584-586. https://doi.org/10.1126/science.1106561

Levine, J. A., \& Miller, J. M. (2007). The energy expenditure of using a "walk-and-work” desk for office workers with obesity. British Journal of Sports Medicine, 41(9), 558-561. https://doi.org/10.1136/bjsm.2006.032755

Levine, J. A., Schleusner, S. J., \& Jensen, M. D. (2000). Energy expenditure of nonexercise activity. The American Journal of Clinical Nutrition, 72(6), 1451-1454.

Lopez-Jimenez, F. (2015). Standing for healthier lives-literally: Figure 1. European Heart Journal, 36(39), 2650-2652. https://doi.org/10.1093/eurheartj/ehv356 
Obesity and Overweight. (n.d.). Retrieved December 3, 2016, from http://www.cdc.gov/nchs/fastats/obesity-overweight.htm

Owen, N., Healy, G. N., Matthews, C. E., \& Dunstan, D. W. (2010). Too Much Sitting: The Population Health Science of Sedentary Behavior. Exercise and Sport Sciences Reviews, 38(3), 105-113. https://doi.org/10.1097/JES.0b013e3181e373a2

Owen, N., Sugiyama, T., Eakin, E. E., Gardiner, P. A., Tremblay, M. S., \& Sallis, J. F. (2011). Adults' sedentary behavior: determinants and interventions. American Journal of Preventive Medicine, 41(2), 189-196.

Pollack, K. M., Sorock, G. S., Slade, M. D., Cantley, L., Sircar, K., Taiwo, O., \& Cullen, M. R. (2007). Association between Body Mass Index and Acute Traumatic Workplace Injury in Hourly Manufacturing Employees. American Journal of Epidemiology, 166(2), 204-211. https://doi.org/10.1093/aje/kwm058

Probert, A. W., Tremblay, M. S., \& Connor Gorber, S. (2008). Desk potatoes: the importance of occupational physical activity on health. Canadian Journal of Public Health $=$ Revue Canadienne De Sante Publique, 99(4), 311-318.

Pronk, N. P., Katz, A. S., Lowry, M., \& Payfer, J. R. (2012). Reducing occupational sitting time and improving worker health: the take-a-stand project, 2011. Preventing Chronic Disease, 9 .

Reiff, C., Marlatt, K., \& Dengel, D. R. (2012). Difference in caloric expenditure in sitting versus standing desks. Journal of Physical Activity and Health, 9(7), 1009-1011.

Sedentary Behaviour Research Networ. (2012). Letter to the Editor: Standardized use of the terms "sedentary" and "sedentary behaviours." Applied Physiology, Nutrition, and Metabolism, 37(3), 540-542. https://doi.org/10.1139/h2012-024 
Sliter, M., \& Yuan, Z. (2015). Workout at work: Laboratory test of psychological and performance outcomes of active workstations. Journal of Occupational Health Psychology, 20(2), 259-271. https://doi.org/10.1037/a0038175

Straker, L., Abbott, R. A., Heiden, M., Mathiassen, S. E., \& Toomingas, A. (2013). Sit-stand desks in call centres: Associations of use and ergonomics awareness with sedentary behavior. Applied Ergonomics, 44(4), 517-522. https://doi.org/10.1016/j.apergo.2012.11.001

Thompson, W. G., Foster, R. C., Eide, D. S., \& Levine, J. A. (2008). Feasibility of a walking workstation to increase daily walking. British Journal of Sports Medicine, 42(3), 225228; discussion 228. https://doi.org/10.1136/bjsm.2007.039479

Thorp, A. A., Owen, N., Neuhaus, M., \& Dunstan, D. W. (2011). Sedentary Behaviors and Subsequent Health Outcomes in Adults. American Journal of Preventive Medicine, 41(2), 207-215. https://doi.org/10.1016/j.amepre.2011.05.004

Wilmot, E. G., Edwardson, C. L., Achana, F. A., Davies, M. J., Gorely, T., Gray, L. J., ... Biddle, S. J. H. (2012). Sedentary time in adults and the association with diabetes, cardiovascular disease and death: systematic review and meta-analysis. Diabetologia, 55(11), 2895-2905. https://doi.org/10.1007/s00125-012-2677-z 


\section{APPENDIX: PARTICIPANT JOB SURVEY}

$\begin{array}{llll}\text { Please circle session: } & \text { Day } 1 \quad \text { Day } 2 \quad \text { Day } 3\end{array}$

\section{Modified Job Boredom Scale:}

Please rate each question with a number 1 to 5

$(1=$ strongly disagree, $2=$ disagree, $3=$ neither agree nor disagree, $4=$ agree, $5=$ strongly agree $)$

1) Did you often get bored with your work today?

2) Did you find your work monotonous?

3) Did you wish to change your type of work to another from time to time?

4) How well do you like the work you do?

5) Did you often get tired throughout the day?

6) Did you find the job dull?

7) Did the day seem to go by slowly?

8) Did you become irritable on the job?

10) Did you feel mentally sluggish during the day?

11) Did you get drowsy on the job?

12) Did the time seem to go by slowly?

13) Were there long periods of boredom?

14) Does your job seem repetitive?

15) During the day, did you find yourself thinking about doing another task?

16) Does monotony describe your job? 


\section{Modified Job Stress Scale:}

On the same scale mentioned above, please rate the following questions.

1) I can accomplish all required tasks during my work day

2) I feel I have control over my life at work

3) I would be more successful if I had more time to complete my work

4) My work is completed to the best of my ability

5) I often feel stressed throughout the day

\section{Modified Job Satisfaction Scale:}

Using the same scale mentioned above, please rate the following.

1) If money were no issue, I would leave my position here

2) Overall, I am satisfied with my job

3) I sometimes feel my job is meaningless

4) I enjoy doing the things I do at work

5) I feel the work I do is important

6) I feel the work I accomplish is appreciated

7) I always know the tasks I am responsible for completing

8) I feel I know what is happening in my department

9) I enjoy working with my co-workers

10) I find I have to work harder than others 